\title{
\begin{tabular}{l|l} 
Mibraries & DSpace@MIT
\end{tabular}
}

\author{
MIT Open Access Articles
}

\section{Teaching and Learning from Environmental Summits: COP 21 and Beyond}

The MIT Faculty has made this article openly available. Please share how this access benefits you. Your story matters.

Citation: Selin, Noelle E. “Teaching and Learning from Environmental Summits: COP 21 and Beyond." Global Environmental Politics 16, no. 3 (August 2016): 31-40. (c) 2016 by the Massachusetts Institute of Technology

As Published: http://dx.doi.org/10.1162/GLEP_A_00364

Publisher: MIT Press

Persistent URL: http://hdl.handle.net/1721.1/114278

Version: Final published version: final published article, as it appeared in a journal, conference proceedings, or other formally published context

Terms of Use: Article is made available in accordance with the publisher's policy and may be subject to US copyright law. Please refer to the publisher's site for terms of use. 


\title{
Teaching and Learning from Environmental Summits: COP 21 and Beyond
}

\author{
Noelle E. Selin*
}

\begin{abstract}
High-profile environmental summits like the recent Paris climate conference (COP 21) offer an opportunity to incorporate real-world, timely issues into teaching and learning about global environmental governance. Using COP 21 as an example, this Forum article summarizes the ways that contemporary environmental summits can be incorporated into university-level education, providing content and context to help address the challenges of interdisciplinary sustainability education. Faculty members have incorporated COP-21-related content in ways ranging from traditional lectures and discussions to field trips, which have contributed to a broad range of course content and learning goals. However, the challenges of including environmental summits in educational settings include knowledge-based, normative, and structural barriers. While environmental summits can be an effective way to incorporate knowledge of global environmental governance into interdisciplinary education, more resources, experimentation, and extensions beyond climate change are needed.
\end{abstract}

With the eyes of the world on Paris in December 2015, the eyes of students were among them. For those of us who teach about global environmental politics, this presented both a challenge and an opportunity. Environmental summits offer high-profile examples of how cooperation and conflict about ways to address environmental challenges happen in real-world settings. The impact of high-profile events like COP 21 extends well beyond the academic community that traditionally studies environmental governance.

While experts in global environmental politics are often well-acquainted with the role and importance of summits, the issues addressed at summits are relevant to a much broader community of scholarship. Addressing large-scale, complex global environmental and sustainability problems like climate change requires mobilizing a broad range of expertise from across disciplines (Holdren 2008), including perspectives on global environmental governance. Future

* This article received support from the US National Science Foundation Atmospheric Chemistry Program under Grant \#1053648. 
researchers and practitioners in a variety of disciplines need training and expertise that prepare them to integrate and apply different types of knowledge to real-world problems. Here, I examine whether environmental summits such as COP $21 \mathrm{can}$ provide content and context to help address this interdisciplinary challenge in sustainability education. Drawing on my own experience incorporating environmental negotiations in classroom education, and on insights from colleagues through an online survey and personal interviews, I reflect on the ways in which faculty members at universities engaged with COP 21, lessons learned, and challenges ahead. I focus on university-level classroom settings (as opposed to educational activities for K-12 students, the general public, or education in other forms than traditional classes) in a broad range of disciplines. First, I summarize the varying ways in which faculty can incorporate environmental summits into education, and assess how this live, real-world content can affect educational outcomes. I then identify challenges and roadblocks to teaching and learning from summits in interdisciplinary settings, including knowledge-based, normative, and structural barriers. Finally, I conclude by recommending concrete ways forward for improved outcomes when incorporating environmental summits in multidisciplinary coursework.

\section{How Can Faculty Incorporate Environmental Summits into Education?}

Over 30,000 people attended COP 21 in Paris as registered delegates (UNFCCC 2015), and numerous others gathered in Paris for conferences and side events during the first two weeks in December 2015. Of the roughly 1,000 nongovernmental organizations (NGOs) represented at COP 21, more than 10 percent were accredited via universities, comprising nearly 700 participants. This is most certainly an underestimate of university and student participation in the proceedings, since numerous faculty and students participated on government delegations, as part of international organizations, or representing non-university NGOs. These students and scholars represented a broad range of disciplines across social science, natural science, and engineering.

Young people, including many students, are officially represented through YOUNGOs, the youth nongovernmental organization coalition, one of nine civil society constituencies specifically recognized by the Framework Convention on Climate Change (FCCC). Other activities taking place concurrently with COP 21 drew even more participants, including gatherings, educational and outreach events, and exhibits throughout Paris. The Conference of Youth (COY), an event held annually before the COP, was particularly relevant to students. Local COY events took place on every continent at the same time as the events in Paris, drawing 4,000 participants in Paris and 2,000 in the rest of the world.

Those who had the opportunity to travel to Paris to witness this historic event, however, represent a small minority of those who encountered some aspects of COP 21 in teaching and learning. COP 21 was relevant to a broad array of course material and learning objectives, ranging far beyond courses traditionally 
taught by global environmental politics scholars. These included classes on climate and environmental science, energy, environmental studies, law, policy, political science, international relations, public health, and many more.

Faculty who connected course material to the ongoing negotiations did so in varying ways, consistent with the broad range of courses to which COP 21 was relevant. ${ }^{1}$ Some incorporated a lecture on the topic or included material in class discussion. Others watched webcasts of plenary negotiation proceedings and/or side events, which were live-streamed online by the UNFCCC. Written materials relevant to the negotiations were broadly available and accessible. Given publication timelines, few books are up-to-date enough to include the most recent information on the Paris Agreement, but several include thorough and recent treatments of the history and context of climate policy leading up to Paris (Betsill 2015; Selin and VanDeveer 2016). Additional literature from both the natural and social sciences offered timely perspectives on specific issues, from examining parties' interests and preferences, to assessing the implications of mitigation targets. Comprehensive and approachable summaries from newspapers and magazines provided perspectives and analysis. In addition to content from traditional news sources, much information - of varying quality and reliability-is available online, in the form of blogs and commentary. Daily reports of negotiations are available from NGOs such as the Earth Negotiations Bulletin and the ECO newsletters from the Climate Action Network. Increasingly, curated online material is produced and published rapidly by academics across the world; one example is The Conversation, which launched in 2013 as an independent source of news and views from the academic and research community, and which published a compilation of COP 21 climate coverage (Hopkin 2015).

Technology plays a key role in enabling large-scale, multidisciplinary learning from current events. It is hard to overstate the tremendous technological changes that have unfolded concurrently with the process of global environmental negotiations in the decades since the 1992 Earth Summit (Depledge and Chasek 2012). A major benefit has been the ability of observers from a broader community, including students, to actively engage in ongoing events. Technological developments are likely to make engagement easier and more reliable in the future. The widespread availability of video conferencing, such as Skype or similar applications, coupled with Internet availability across the Le Bourget site, meant that those on site in Paris could communicate easily with their counterparts across the world. Social media and other Web 2.0 technologies also played an important and growing role (Tess 2013). Twitter users using the \#COP21 hashtag participated in a global community discussion, with more than one million total tweets over the course of the event, and the number of tweets per hour topped 60,000 at key moments in the negotiations. Twitter even

1. This information was gained from an online survey, conducted by the author in February 2016, of faculty members and students who taught or participated in courses with content relevant to COP 21. In all, twenty-eight faculty members responded to the survey. The majority of respondents were from US institutions (85\%), and the remainder were from Europe. 
introduced a custom emoji featuring the COP 21 logo. Several university classes incorporated online communication via Twitter, facilitating dialogue as well as connections between different universities.

\section{How Does Incorporating Climate Summits Affect Learning Outcomes?}

A large body of research supports the idea that active learning can improve student engagement and, ultimately, learning (Prince 2004). Faculty teaching about concepts related to global environmental governance has often incorporated active learning through role-playing exercises or mock negotiations. These interactive methods have been proposed as a strategy to engage students in building both content and process-based knowledge (Susskind and Corburn 2000; Stokes and Selin 2014). For example, the WorldClimate simulation (Sterman et al. 2015) has to date been played by over 10,000 participants, including numerous classrooms, as well as with policy-makers and the general public. Engaging with real-time negotiations extends and broadens this type of teaching method and facilitates its adoption in a broader range of courses.

Faculty and student feedback on experiences during COP 21 showed that incorporating these types of real-world applications into classroom settings helped achieve a variety of learning goals relevant to sustainability education across disciplines. ${ }^{2}$ Classes with a focus on governance issues aimed to teach familiarity with the institutions and actors that shape global environmental politics, key concepts in policy and governance, and factors that affect environmental cooperation. Other relevant learning goals included understanding the interactions of science and technology with international affairs, the history and theory of environmental cooperation, and the different methods and approaches to environmental regulations. However, in a number of natural science and engineering classes, the goals addressed different topics, such as enhancing knowledge of climate science in perspective, understanding the international dimensions of pollution problems, and evaluating discussions of climate change on the basis of scientific evidence and organized knowledge. Overall, across a broad range of disciplines, faculty agreed that incorporating material on COP 21 improved student learning, enhanced interest in the subject matter, and increased student enjoyment. ${ }^{3}$

In addition to learning goals focused on subjects and concepts, several classes used COP 21 to enhance learning on more general academic skills, such as communication, writing, and analysis. ${ }^{4}$ The high-profile nature of environmental summits offers a unique opportunity to learn, practice, and refine communication skills. In many classes student writing was posted on the Web, where students had the opportunity to share their perspectives broadly. Examples of

2. Online survey conducted by the author, 2016 .

3. Online survey conducted by the author, 2016.

4. Online survey conducted by the author, 2016. 
these are blogs by students at Stanford, the University of Toronto, Williams College, and many others. ${ }^{5}$

In addition to learning-related benefits for students themselves, participation by students in environmental summits can have substantial societal benefits, as well. A relevant example of this comes from the contributions of two university students from New Zealand, attending COP 21 as part of a youth NGO, whose notes from the proceedings in a Google document were credited by mainstream media sources as providing the best public record of ongoing negotiations (Holthaus 2015). Students have also served as advisors for countries and NGOs by providing support with research, writing, and analysis. For example, students from Duke University's Nicholas School of the Environment participated in COP 21 as expert consultants for participating countries or NGOs, offering knowledge and perspectives to the international process (Lewis 2016). In another example, a group of students from fifteen historically black colleges and universities in the US sent representatives to COP 21 to offer perspectives on environmental justice and equity, working with community organizations (Deep South Center for Environmental Justice 2016). Even for students who do not attend negotiations in person, observing and learning about the wide participation of young people in global environmental negotiations can reinforce the idea that students from a broad range of backgrounds can make a difference in the world.

\section{What Are the Major Challenges?}

While many educators successfully incorporated relevant learning opportunities from COP 21 in classroom settings, several barriers to more widespread adoption of environmental summit-related content remain, especially for courses in disciplines beyond those that are traditionally the domain of global environmental politics scholars. These include knowledge-based, normative, and structural barriers.

Knowledge-based barriers involve the capacity of faculty members to understand the complex interactions that characterize the climate change issue. The basic structure and context of global environmental agreements such as the FCCC are familiar to scholars of and educators in global environmental politics. However, faculty members in other disciplines-especially those in the natural sciences and engineering-can be less prepared to teach this material. For example, physical scientists teaching courses on climate or environmental science often attempt to incorporate material showing the relevance of such material to society. However, many scientists lack specific knowledge about or training in environmental policy and negotiation. Some faculty members also lack experience and expertise with using new technology and online tools,

5. These blogs can be found at www.climate-stories.org (Stanford), www.utcop21.org (Toronto), and http://sites.williams.edu/cop21/blog-posts/ (Williams). 
and are therefore hesitant to fully embrace them in classroom settings, especially where troubleshooting may be necessary or technical difficulties may occur.

Another knowledge-based barrier is that when teaching about ongoing events, the knowledge required is constantly changing. Incorporating real-world events into classes challenges our ability as educators to present carefully curated content and clear, defined outcomes. Notwithstanding some high-profile prognostications by university faculty in the media, it was impossible to know the Paris Agreement outcome before it happened, even for global environmental politics experts. This meant that educators teaching a class incorporating COP 21 needed to clarify, interpret, and reflect on the emerging agreement on the fly. In addition, there is always the potential for surprising events that affect outcomes in unpredictable ways. For example, the November 2015 terrorist attacks in Paris, a few short weeks before COP 21, altered plans for both civil society gatherings and head-of-state security, and changed the discourse about the development of a potential agreement. ${ }^{6}$

Normative barriers include the challenges of incorporating diverse opinions and ensuring accessibility. Encouraging student engagement in real-world events should be conducted carefully, and faculty need to consider norms, expectations, and legal frameworks to be inclusive of all students. Like faculty, students have different beliefs and preferences on policies and strategies to combat climate change. Encouraging productive rather than destructive debate in the context of sometimes contentious and polarized issues can be challenging. In the United States, incorporating social media as part of a course also requires careful attention to federal educational privacy law (Gertin 2014). Specifically, this law forbids faculty from revealing the identity of students involved in courses; for this reason, requiring students to create and post material online risks violating that law unless students are given explicit alternatives for credit. Accessibility to all students can also be an important consideration. For example, the UN FCCC webcasts, and much other video material provided by organizations such as Earth Negotiations Bulletin, do not include closed captioning, which can limit participation by students who are deaf or hard of hearing. Also, understanding real-time negotiations can be difficult for those who are not native speakers of one of the six UN languages (or perhaps may not understand any of these languages at all).

Structurally, several challenges are relevant to incorporating real-world events into standard university courses. For example, COP 21 was scheduled to take place from November 30 to December 11, 2015 (and did not fully wrap up until the evening of December 12). For some universities, this meant that the end of negotiations extended past the end of fall semester, into exam periods

6. McGrath, Matt. COP21: Paris Climate Deal "More Likely" After Terror Attacks. BBC News, November 29, 2015. Available at www.bbc.com/news/science-environment-34950442, accessed April 19, 2016. 
or winter break. Even where COP 21 fell within the dates of scheduled class offerings, students taking more than one class at a time, and faculty teaching more than one class, may not have been able to travel, or even to fully engage with events that did not necessarily occur during scheduled classroom hours.

The 24-hour nature of activities as negotiations approach (and overshoot) deadlines creates another type of structural barrier. This schedule means that no matter where in the world you are, something is likely to happen outside of your working or waking hours. Flexible or modular course schedules, already used in many universities, could help make participation in events easier. Educators in global environmental politics may consider advocating for change on their own campuses, where they might usefully partner across disciplines with those who hope to encourage other real-world engagement, such as cooperative work experience, field trips, or extended laboratories (Whitmeyer and Mogk 2009). Even when schedules allow, incorporating travel to negotiations can be logistically challenging-including issues of accreditation, which can be difficult for individual faculty members to accomplish if a university, research center, or collaborating NGO is not already registered as an observer. Also, a substantial financial burden is associated with international travel, and resources for such initiatives are limited.

\section{What Is Needed to Improve Education?}

While events and outcomes as high-profile as COP 21 and the Paris Agreement might happen only a few times in our careers as educators, the lessons from this experience can nevertheless be incorporated into standard curricula across a broad range of relevant disciplines. Environmental summits can provide a high-profile, timely opportunity for global environmental governance knowledge to be incorporated in multidisciplinary sustainability education. To facilitate broader adoption of summit-based education toward this goal, there are needs for more resources, more experimentation and evaluation, and applications beyond climate change.

First, providing more resources-in the forms of both curricular materials and financial support for travel and course development-would enable a broader diversity of faculty members to incorporate environmental summit-related activities into classrooms. Global environmental politics scholars can help by providing materials and curricular modules that are accessible to faculty with a broad range of backgrounds. Several initiatives have begun to collect course materials and resources, and have made these accessible. For example, a repository of course syllabi and negotiation simulations is available online through the IUCN Academy of Environmental Law. ${ }^{7}$ Beyond these important efforts, however, information on the policy, governance, legal, and social aspects of climate change designed for 
educators is less broadly available than resources for teaching climate science. Building on the materials available on the scientific and technical aspects of climate change, several further opportunities for collective action could help make educational resources more broadly available. Professional organizations or societies could play a convening or organizing role, especially those with interests in global climate and policy, such as the American Association for the Advancement of Science. Efforts such as Global Climate Change Week, ${ }^{8}$ drawing thousands of academics across the world, are examples of universities acting together to facilitate engagement and connections. Organizations that provide fellowships and professional development opportunities for faculty members could also consider financial and logistical support for faculty to attend environmental negotiations, to help educate them about how the process works.

Second, more formalized experimentation and evaluation are necessary to measure learning outcomes and experiences for students in this area. Improving education across disciplines on complex sustainability challenges like climate change, and preparing students to address them in the future, requires new strategies that go beyond traditional teaching methods. While many educators are experimenting with new ways of teaching in this area, markedly fewer are conducting rigorous evaluation and publishing in the educational literature. Such evaluations would help identify best practices in an increasingly interdisciplinary educational landscape.

Finally, educators should embrace the opportunity to teach about environmental summits other than those on climate change. With over 1,000 multilateral environmental agreements across different issues, and climate change action happening at all levels of governance, opportunities for student engagement can be both timely and local. International cooperation on topics such as chemicals, mercury, ozone depletion, biodiversity, and desertification can provide important lessons about governance (Dauvergne and Clapp 2016), as well as opportunities for more direct interaction with decision-makers. For example, parties to the Montreal Protocol, a case study of environmental governance used in many courses, meet annually. For chemicals and biodiversity conventions, COPs are held normally every two years, with technical meetings of subsidiary bodies meeting between COPs. In addition, as scholars of global environmental politics know quite well, often the decisions made in the everyday processes of institutions and politics have the largest effects on the environment and the world. In that spirit, the next climate negotiation, COP 22, is scheduled for November 7-18, 2016, in Marrakesh, Morocco.

\section{References}

Betsill, Michele M. 2015. International Climate Change Policy: Complex Multilevel Governance. In The Global Environment: Institutions, Law, and Policy, 4th edition, edited

8. See http://globalclimatechangeweek.com, accessed April 19, 2016. 
by Regina S. Axelrod and Stacy D. VanDeveer, 234-258. Washington, DC: CQ Press.

Dauvergne, Peter, and Jennifer Clapp. 2016. Researching Global Environmental Politics in the 21st Century. Global Environmental Politics 16 (1): 1-12.

Deep South Center for Environmental Justice. 2016. HBCU Climate Change Delegation Converge on COP21 in Paris. Blog Post, January 29. Available at http://bit.ly/ 1PBPQ5G, accessed April 19, 2016.

Depledge, Joanna, and Pamela S. Chasek. 2012. Raising the Tempo: The Escalating Pace and Intensity of Environmental Negotiations. In The Roads from Rio: Lessons Learned from Twenty Years of Multilateral Environmental Negotiations, edited by Pamela M. Chasek and Lynn M. Wagner, 19-38. New York: RFF Press.

Gertin, Laura. 2014. Before You Set a Hashtag for Your Course or Have Students Blog, Think FERPA. Blog Post, American Geophysical Union GeoEd Trek, August 14. Available at http://blogs.agu.org/geoedtrek/2014/08/20/hashtag-blog-ferpa/, accessed April 19, 2016.

Holdren, John P. 2008. Science and Technology for Sustainable Well-Being. Science 319: 424-434.

Holthaus, Eric. 2015. World Leaders Met to Save the Planet, and the Only Full Public Record Is This Google Doc. Blog Post, Slate, December 4. Available at http://slate.me/1Qla0OI, accessed April 19, 2016.

Hopkin, Michael. 2015. Beyond Paris: What Was Really Achieved at the COP21 Climate Summit, and What Next? The Conversation, December 16. Available at http://bit.ly/ 1QrNHZm, accessed April 19, 2016.

Lewis, Lyndsi. 2016. COP21 in Review: What Students Learned at the World's Biggest Climate Conference. Blog Post, Nicolas School of the Environment, February 11. Available at http://bit.ly/1UaJ5rx, accessed April 19, 2016.

Prince, Michael. 2004. Does Active Learning Work? A Review of the Research. Journal of Engineering Education 93 (3): 223-231.

Selin, Henrik, and Stacy D. VanDeveer. 2016. Global Climate Change Governance: The Long Road to Paris. In Environmental Policy: New Directions for the Twenty-First Century, 9th edition, edited by Norman J. Vig and Michael E. Kraft, 288-310. Washington, DC: CQ Press.

Sterman, John, Travis Franck, Thomas Fiddaman, Andrew Jones, Stephanie McCauley, Philip Rice, Elizabeth Sawin, Lori Siegel and Juliette N. Rooney-Varga. 2015. World Climate: A Role-Play Simulation of Climate Negotiations. Simulation and Gaming 46 (3-4): 348-382.

Stokes, Leah C., and Noelle E. Selin. 2014. The Mercury Game: Evaluating a Negotiation Simulation that Teaches Students About Science-Policy Interactions. Journal of Environmental Studies and Science. Advance online publication. doi:10.1007/ s13412-014-0183-y.

Susskind, Lawrence, and Jason Corburn. 2000. Using Simulations to Teach Negotiation: Pedagogical Theory and Practice. In Simulation und Planspiel in den Sozialwissenschaften: Eine Bestandsaufnahme der Internationalen Diskussion, edited by Dietmar Herz and Andreas Blätte, 62-90. Münster, Germany: Lit Verlag.

Tess, Paul A. 2013. The Role of Social Media in Higher Education Classes (Real and Virtual)-A Literature Review. Computers in Human Behavior 29: A60-A68. 
United Nations Framework Convention on Climate Change (UNFCCC). 2015. List of Participants. Part 3: Intergovernmental Organizations (East African Community-The Regional Organization for the Conservation of the Environment of the Red Sea and Gulf of Aden); Non-Governmental Organizations. United Nations Office at Geneva, Switzerland, December 11. FCCC/CP/2015/INF.3. Available at http:// unfccc.int/resource/docs/2015/cop21/eng/inf03p03.pdf.

Whitmeyer, Steven J., and David W. Mogk. 2009. Geoscience Field Education: A Recent Resurgence. Eos: Transactions of the American Geophysical Union 90 (43): 385-387. 